\title{
Evidence to Achieve an Optimal Model for Children's Health in Europe
}

\author{
Mitch Blair, Michael Rigby and Denise Alexander
}

\begin{abstract}
Models of Child Health Appraised (MOCHA) was a wide-ranging, multidisciplinary and multi-method study that aimed to identify the best models of provision of primary care for the children of the European Union. The research has identified two main conclusions: (1) The depth of interdependency of health, economy and society. Primary care needs to be an active partner in public debate about current child health concerns. It should orientate more effectively in addressing wider societal influences on child health through advocacy and collaborative intersectoral public health approaches with those agencies responsible for public and community health if it is to address effectively issues such as childhood obesity, mental health and vaccine hesitancy. As part of this, it needs to address its workforce composition and skills, not least in two-way communication. (2) The European Community has many visions and commitments to children and child health policies, but their effectiveness is largely unfulfilled. The Commission can strengthen its impact on children's health and healthcare services within current remits and resources by focusing on a number of key fields: planned and structured research, providing insight into optimal human resources and skills in child primary care, developing and using ethical means of listening to children's views, remedying the invisibility of children in data, measuring the quality of primary care from a child-centric perspective, understanding the economics of investing in children's health, developing e-health standards and evaluation, collaborative and harmonised use of downloaded research databases, understanding and respecting children's rights and equity, and appreciating and allowing for children's evolving autonomy as they grow up. An optimal model of primary care for children is proactive, inclusive, corporately linked, based on and providing
\end{abstract}

(C) European Commission. Published by Emerald Publishing Limited. This chapter is published under the Creative Commons Attribution (CC BY 4.0) licence. Anyone may reproduce, distribute, translate and create derivative works of this chapter (for both commercial and non-commercial purposes), subject to full attribution to the original publication and authors. The full terms of this licence may be seen at http://creativecommons.org/licences/by/4.0/legalcode 
robust evidence, and respects the wider determinants of health and children's involvement in their health trajectory.

Keywords: Child; primary care health services; optimum models; health outcomes; intersectoral; interdependency; autonomy

\section{Introduction}

As indicated in the opening chapter of the Models of Child Health Appraised (MOCHA) report (Chapter 1), this large-scale comprehensive project was established to use research to identify the best models for provision of effective primary care for the children of Europe. In a wide-ranging multidisciplinary and multi-method study, it achieved many scientific results but was not able to deliver the holy grail of an optimum model, or choice of validated models. In this respect we agree with the findings of the European Commission Expert Group on Health Systems Performance (2016), which recently noted:

While highlighting variations between countries, it is often difficult for practitioners and policy makers to interpret what a country positioning means in terms of performance, and what policy action should be taken in order to improve performance.

But what MOCHA has established, as described in detail in its deliverables, and in summary in the 19 chapters of this volume of integrated results, is two things:

(1) the depth of interdependency of health, economy and society; and

(2) the European Community has many visions and commitments to children, and child and health-related policies, but the effectiveness is largely unfulfilled because there is no Model for European commitment to children.

While these may have been understood as truisms by many, an achievement of MOCHA has been to use scientific scrutiny to assess the many aspects of health and health care for children that make these two conclusions stand out so strongly.

Meanwhile, one of the founding questions that led to creation of the MOCHA project proposal - 'Which type of primary care doctor is better for delivering effective primary care for children?' - has been shown to be marginal on two grounds: the modest (though clearly important) role of doctors and indeed health care on children's health compared to the greater influence of the wider determinants (Chapter 9) and the demographic dynamic within the medical workforce which itself is changing the pattern of primary care practice for children (Chapter 13). 


\section{Intertwining of Health, Economy and Society}

\section{Economic Context}

All citizens, and particularly children, are deeply influenced by their social and physical environments. The preconditions for good parenting and provision of a safe and learning rich home environment is highly dependent on adult security which is considerably influenced by the economy of the country and on the services available to support the family. And in turn those providing services, not least health services, are dependent on the national economy to fund those services, either directly through taxation of though a vibrant insurance system.

Thus, the well-being of the economy has major effects on the health of children in profound ways. In an attempt to look at overall effects, and also the progress of countries in improving the health of their children, in the absence of meaningful comparable illness or morbidity rates (see Chapter 7), the MOCHA study examined trends in mortality in young adults, after the end of the complete period of childhood. Hypothesising that deaths of young adults other than in accidents were in great part likely to be the outcome of the health services and determinants received throughout their childhood, we extracted data for the 30 study countries, showing numbers and rates, absolute change and rate of change in the past decade, and these are presented in Table 19.1.

Economic data for these countries are shown in Chapter 9 and confirm the effect, but what Table 19.1 shows is the strong gradient from the poorer New Member States countries to the more affluent countries, and also the progress being made by these countries in improving the standards of primary medical care. For example, increasing use of guidelines and evidence-based medicine, primary care staffing and e-health together with improved social and economic policies to support poor nutrition and housing and other upstream determinants of child health appear to be yielding strong gains.

In this setting, the type of doctor, and the skill mix, is less important than their knowledge and use of latest relevant evidence and their optimal utilisation of the available resources. We return to this theme in the context of harmonisation later, while details of workforce and education are the subject of Chapter 13.

\section{Societal Context}

We looked at the societal context of the delivery of primary care in five ways. First, Chapter 3 reports on how we undertook direct interviewing of children and parents in five very different European countries and found some strong threads. Health services need to be sensitive to needs, delivered in a nonpatronising way and accessible in physical, economic and social meanings of accessibility. Secondly, as also reported in that chapter, we undertook societal studies on expectations of and attitudes to primary healthcare services for children. Thirdly, we undertook detailed study of the evolution of current societal attitudes to children, and the importance in the twenty-first century of taking a 
Table 19.1. Total non-accidental deaths and Rate of Change in 20-24-yearolds (2006-2016) (GBD Study).

\begin{tabular}{|c|c|c|c|c|c|c|c|c|c|c|c|c|}
\hline \multirow[b]{2}{*}{ Country } & \multicolumn{4}{|c|}{$\begin{array}{l}\text { Rate of Mortality (Per 100k), Both } \\
\text { Genders }\end{array}$} & \multicolumn{4}{|c|}{ Rate of Mortality (Per 100k), Males } & \multicolumn{4}{|c|}{ Rate of Mortality (Per 100k), Females } \\
\hline & 2006 & 2016 & $\begin{array}{l}\text { Absolute } \\
\text { Change }\end{array}$ & $\%$ Change & 2006 & 2016 & $\begin{array}{l}\text { Absolute } \\
\text { Change }\end{array}$ & $\%$ Change & 2006 & 2016 & \begin{tabular}{|l} 
Absolute \\
Change
\end{tabular} & $\%$ Change \\
\hline Austria & 20.54 & 15.63 & 4.91 & -23.90 & 26.48 & 19.48 & 7.00 & -26.44 & 14.48 & 11.61 & 2.87 & -19.82 \\
\hline Belgium & 14.33 & 11.85 & 2.48 & -17.31 & 18.03 & 14.15 & 3.88 & -21.52 & 10.60 & 9.47 & 1.13 & -10.66 \\
\hline Bulgaria & 33.41 & 28.26 & 5.15 & -15.41 & 41.69 & 35.82 & 5.87 & -14.08 & 24.56 & 20.34 & 4.22 & -17.18 \\
\hline Croatia & 21.20 & 17.36 & 3.84 & -18.11 & 27.10 & 21.90 & 5.20 & -19.19 & 15.07 & 12.60 & 2.47 & -16.39 \\
\hline Cyprus & 21.12 & 16.89 & 4.23 & -20.03 & 26.77 & 22.82 & 3.95 & -14.76 & 15.27 & 10.74 & 4.53 & -29.67 \\
\hline Czech Rep. & 17.32 & 14.53 & 2.79 & -16.11 & 21.80 & 17.61 & 4.19 & -19.22 & 12.59 & 11.28 & 1.31 & -10.41 \\
\hline Denmark & 17.59 & 13.88 & 3.71 & -21.09 & 23.55 & 16.49 & 7.06 & -29.98 & 11.45 & 11.15 & 0.30 & -2.62 \\
\hline Estonia & 47.09 & 31.23 & 15.86 & -33.68 & 65.03 & 43.92 & 21.11 & -32.46 & 28.24 & 17.52 & 10.72 & -37.96 \\
\hline Finland & 23.34 & 17.86 & 5.48 & -23.48 & 32.01 & 25.12 & 6.89 & -21.52 & 14.27 & 10.27 & 4.00 & -28.03 \\
\hline France & 14.94 & 12.15 & 2.79 & -18.67 & 17.78 & 14.65 & 3.13 & -17.60 & 12.09 & 9.59 & 2.50 & -20.68 \\
\hline Germany & 15.43 & 12.64 & 2.79 & -18.08 & 18.80 & 15.03 & 3.77 & -20.05 & 11.98 & 10.12 & 1.86 & -15.53 \\
\hline Greece & 23.24 & 19.41 & 3.83 & -16.48 & 32.65 & 25.48 & 7.17 & -21.96 & 13.12 & 13.00 & 0.12 & $-0.91 \%$ \\
\hline Hungary & 18.83 & 15.92 & 2.91 & -15.45 & 22.95 & 19.43 & 3.52 & -15.34 & 14.56 & 12.20 & 2.36 & -16.21 \\
\hline Iceland & 19.00 & 16.36 & 2.64 & -13.89 & 23.22 & 17.27 & 5.95 & -25.62 & 14.65 & 15.38 & -0.73 & 4.98 \\
\hline Ireland & 22.36 & 20.24 & 2.12 & $-9.48 \%$ & 29.76 & 28.01 & 1.75 & -5.88 & 14.82 & 11.92 & 2.90 & -19.57 \\
\hline Italy & 14.50 & 12.53 & 1.97 & -13.59 & 18.16 & 15.49 & 2.67 & -14.70 & 10.71 & 9.42 & 1.29 & -12.04 \\
\hline Latvia & 31.80 & 22.49 & 9.31 & -29.28 & 43.00 & 27.40 & 15.60 & -36.28 & 20.04 & 17.22 & 2.82 & -14.07 \\
\hline Lithuania & 32.45 & 23.71 & 8.74 & -26.93 & 44.96 & 32.51 & 12.45 & -27.69 & 19.59 & 14.43 & 5.16 & -26.34 \\
\hline Luxembourg & 19.20 & 14.45 & 4.75 & -24.74 & 24.99 & 16.61 & 8.38 & -33.53 & 13.13 & 12.17 & 0.96 & $-7.31 \%$ \\
\hline Malta & 21.61 & 17.02 & 4.59 & -21.24 & 26.28 & 22.34 & 3.94 & -14.99 & 15.94 & 12.22 & 3.72 & -23.34 \\
\hline Netherlands & 13.31 & 11.16 & 2.15 & -16.15 & 15.23 & 13.39 & 1.84 & -12.08 & 11.36 & 8.88 & 2.48 & -21.83 \\
\hline Norway & 24.95 & 18.14 & 6.81 & -27.29 & 32.84 & 24.29 & 8.55 & -26.04 & 16.78 & 11.59 & 5.19 & -30.93 \\
\hline Poland & 18.38 & 16.27 & 2.11 & -11.48 & 23.91 & 21.27 & 2.64 & -11.04 & 12.67 & 11.04 & 1.63 & -12.87 \\
\hline Portugal & 19.31 & 15.78 & 3.53 & -18.28 & 22.20 & 18.67 & 3.53 & -15.90 & 16.34 & 13.84 & 2.50 & -15.30 \\
\hline Romania & 28.46 & 28.89 & -0.43 & $1.51 \%$ & 34.01 & 34.48 & -0.47 & $1.38 \%$ & 22.59 & 22.93 & -0.34 & $1.51 \%$ \\
\hline Slovakia & 19.93 & 16.85 & 3.08 & -15.45 & 25.33 & 20.70 & 4.63 & -18.28 & 14.27 & 12.83 & 1.44 & -10.09 \\
\hline Slovenia & 16.58 & 12.25 & 4.33 & -26.12 & 20.89 & 15.16 & 5.73 & -27.43 & 12.05 & 9.22 & 2.83 & -23.49 \\
\hline Spain & 14.92 & 11.12 & 3.8 & -25.47 & 18.60 & 13.31 & 5.29 & -28.44 & 11.05 & 8.84 & 2.21 & -20.00 \\
\hline Sweden & 17.55 & 16.95 & 0.6 & $-3.42 \%$ & 23.00 & 23.58 & -0.58 & $2.52 \%$ & 11.86 & 9.97 & 1.89 & -15.94 \\
\hline UK & 22.58 & 18.57 & 4.01 & -17.76 & 28.76 & 23.10 & 5.66 & -19.68 & 16.36 & 13.88 & 2.48 & -15.16 \\
\hline
\end{tabular}


Table 19.1. (Continued)

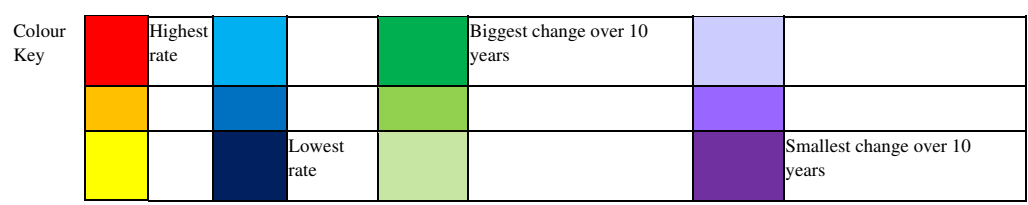

Notes: *Rate per $100 \mathrm{k}$ population of $20-24$-year-olds.

**Accidents (excluded) include transport injuries, road injuries, unintentional injuries, exposure to mechanical forces, animal contact, foreign body, self-harm and interpersonal violence, forces of nature, conflict and terrorism, and executions and police conflict.

Data extracted from the results tool from the Global Burden of Disease study. Presentation: S. Deshpande

child-centric view throughout, reported in Chapter 4. Fourthly, we ascertained from all countries the child health-related issues that had hit the headlines or in other ways attracted strong societal interest, looking particularly at triggers and expectations (Chapter 17). Fifthly, we took three approaches to researching what changes to services would be acceptable and indeed hoped for. One was a sample public attitude study on attitudes to health services for children (van Til, Groothuis-Oudshoorn, \& Boere-Boonekamp, 2018). The second asked a number of stakeholders in a range of countries their attitudes to a number of child primary care policy issues (Kocken, Vlasblom, de Lijster, \& Reijneveld, 2018). And as a collation of all these issues in a policy change context, we looked at theories and practice on transferability of policy and evidence to new settings, and the societal environment featured in this (Schloemer, \& Schröder-Bäck, 2018; Zdunek, Schroder-Back, Rigby, \& Blair, 2018).

All these studies initiated by MOCHA in public consultation were inevitably small, and not statistically significant in quantitative science terms, but our mixed and varied methods and sources should be enough to show the importance of society as the operational context of primary care services. And in a different way, Chapter 14 raised the use of social media and health, being not only a potential threat and risk, but also a new modality for delivering knowledge and care.

So from this brief summary, but more so from the variety of society-related studies in the detailed MOCHA work and reported on the website www.childhealthservicemodels.eu, it is clear that society is strong, complex and has its own dynamics. Primary care for children cannot operate effectively in defiance of society (vaccine resistance and increasing child obesity are immediate examples of this), but also good primary care services are expected by society, and indeed, health services should be the servant of the people and not a meritocracy operating in isolation. Health service leaders must contribute to societal debate and influences, but, in a way, which is acceptable to society in a wider sense. 
So for this reason too, it is not possible to define a single optimal model of child primary care provision. Instead, health systems need to be in harmony in the context of the society within which it operates, while also being evidence-based.

\section{Health Policy and Provision in the European Community Context}

A complexity in undertaking any research on health policy in EU countries is that that policy and operation of health services, and also social care and welfare services, are the prerogative and competency of individual member states. The European Commission itself has no competency in health care and cannot intervene in states' policies. However, in addition to the European endeavour of boosting member states' economies through free trade and development of social standards and thus benefiting health and health care, the Commission has three core functions which directly can enable primary healthcare systems across Europe: Research, Information and Communication Technologies (including e-health) and Public Health.

Additionally, there are activities related to harmonising Education and Training and addressing Social Inclusion. Finally, there are support and monitoring functions. Eurostat is the most relevant example of a support function, as reliable comparative data are an important tool in assisting policy-makers and service providers, while the Fundamental Rights Agency defines rights including those of children. Monitoring includes the function of DG Justice for monitoring implementation of the United Nations Convention on the Rights of the Child by member states.

However, there is no clear mechanism whereby this significant set of functions, and respective Directorates General, harmonises their work either on a topic basis or more generally on either health issues or children's interests. From our findings, we assess that there is considerable scope for the Commission to strengthen its impact on children's health and healthcare services, within current remits and resources, and based on its vision of a knowledge-based economy enabling European solidarity though robust collaborative member states.

Of course, the European Commission works within the wider geographical compass to the European Regional Office of the World Health Organization, and in June 2018, the Health Ministers for the whole of Europe met in Tallinn and confirmed a shared vision on Health Systems for Prosperity and Solidarity: leaving no one behind (World Health Organization Regional Office for Europe, 2018). That vision featured, additional to investment, Inclusion and Innovation. The meeting committed to Solidarity. We see these intentions as exactly what is needed within Europe to progress the strengths of the Commission to support better primary care for Europe's children. We share this vision in the next section, based on our findings and our frustrations. 


\section{Potential for the EU to Boost Primary Care for Children within Existing Actions}

The MOCHA project has identified a number of potential areas for more focused research, and policy and service development described in the next sections.

\section{Optimal Human Resources in Child Primary Care}

The workforce is the biggest resource in any health system and the more so in primary care. We have identified in Chapter 13, the unsatisfactory situation in which there is no knowledge or evidence about optimal professional mix, or the most needed and productive skills within professions and how to assure these. There is a clear requirement for research in this area, not only because of the urgency now becoming apparent with the rapidly shifting demography of primary care providers but also to ensure appropriate training of the workforce to optimally meet the needs of children and young people now and in the future. In Chapter 13, we identify significant differences in basic education patterns for medical doctors, and even more so for nurses. There is also a European risk here, in that, these are mutually recognised qualifications between European Member States, yet there is not a matching of skills and competencies.

DG Employment, Social Affairs and Inclusion (2018) is responsible for the European Skills/Competences, Qualifications and Occupations (ESCO) initiative which has a section for Health Professionals. However, this seems to stop at a high level. Meanwhile DG Education and Culture have responsibility for harmonisation of third-level education across Europe, but there is limited harmonisation of contents even when related to professional competencies leading to mutually accepted profession recognition.

From the totality of the findings in Chapter 13, we can identify the potential significant benefit if research could be addressed to identify optimal medical and nursing knowledge and competencies, which in turn could lead to strengthening of the ECSO reference skill sets. European children would benefit from better, more effective and safer services.

\section{Ethical means of Listening to Children}

We were able, within the scope of MOCHA, to interview 81 children in five countries, reported in Chapter 3. The value to the project in terms of clarifying patient and parent perceptions about how the health system works for the individual was enormous and helped to inform development of standards and give insight onto some of the important issues such as coordination and communication skills with professionals. A recommendation would be the development of the tools we used successfully, to create a more systematic and representative survey across Europe about experiences. This could also build on the experience 
of the country agent reports on participation of children and young people in such surveys.

Europe has successfully developed the European Health Interview Survey and the European Health Examination Survey, which enable compilation of comparative data, and there is a European Health Interview \& Health Examination Surveys Database website (https://hishes.wiv-isp.be/index.php? hishes=home). When these survey tools were designed more than a decade ago, children were excluded for reasons of methodology. However, with the development of techniques such as those applied by MOCHA, the exclusion of the voices of children is no longer defensible. Work is needed to create for children the tools and knowledge bases now in existence for adult citizens.

\section{Improving the visibility of children in data}

A large part of the project has required the hunting down of key clinical, epidemiological, workforce and economic data related to children and their services - Chapter 7 details this. In fact, often the analyses are not available, but at field capture level, the data are there. Adding appropriate coding and analysis is not a large job in the total system of data assembly, but is not done, and children are the victims. This is not a new problem. For example, the Child Health Indicators of Life and Development project was co-funded in 2000-2002 by the European Commission to give visibility to children through a planned balanced indicator set (Rigby, Köhler, Blair, \& Mechtler, 2003), but has never been actioned. Our scientific understanding of the importance of life course development and its importance for human potential has grown since then. There is increased recognition that both vertical and horizontal integration of services is a necessity to tackle the latest forms of morbidity and enhance wellbeing. We cannot afford to wait another 18 years to agree and actively use an appropriate set of shared measures and outcomes in the whole child health system which reflects these two dimensions.

However, there are good examples of such harmonisation in the area of perinatal health (http://www.europeristat.com/) and also neonatal intensive care, which has an extensive network across Europe. Many disease registers also have European harmonisation requirement and those that are linked to clinical networks of health professionals, including public health, have higher quality information on which to base policy and practice. However, the full age range of children and the full range of health and health-related conditions are still excluded from virtually all European data systems. In effect, European statistical systems do not honour the United Nations Convention on the Rights of the Child.

There are also good examples of the use of e-health in the more recent EU countries, for example Estonia and Slovenia, where they have been able to leapfrog technology and provide national scale data on linked primary and specialist care data allowing the possibility of assessing the contribution of different parts of the health system to health outcomes. 
The European Child Public Health Observatory network could provide a data infrastructure which would allow for the monitoring of child health trends over time in different countries and potentially give an early warning to systems about emerging issues and provide information to help plan services in member states. It would also enhance the monitoring of child health against the Region's WHO strategy for child and adolescent health.

\section{Improving the Measurement of Child Primary Care Quality}

Most techniques for measuring the quality of primary care tend to have little focus on children's care. MOCHA has found the PHAMEU initiative to measure the quality of primary care (Kringos, Boerma, van der Zee, \& Groenewegen, 2013) has been widely used but this initiative is set for all ages. However, our own surveys of stakeholders indicates the desirability of developing a framework which takes into account both the development of the child and young person over time and the necessity to consider the different domains of structure process and outcome in relation to children and young people more carefully, for example when considering access, continuity and advocacy for this age group.

\section{Investing in Child Health}

It is incredibly difficult to identify the spend on and the activity of health services for children, as elaborated in Chapters 7 and 9. In order for spend to be optimised, innovative means of identifying financial spend on children and return on investment need to be developed. An actuarial approach across the life course would help policy-makers to exercise some choice in policy options. The Commission has an Expert Panel on Innovative Ways of Investing in Health (https://ec.europa.eu/health/expert_panel/home_en), and we would see merit in linkage with other activities so as to give evidence-based guidance on costeffective and actuarially based investments which would benefit children's health (such possibly as professional education, evaluated prevention programmes and e-health).

\section{Improving Child Centric e-Health Standards and Evaluation}

DG CONNECT leads an active e-health research and development programme. However, our work on e-health found little focus on children despite their health service needs and also their being eager users of social media and health technologies - including exposure to un-validated ones with potential risks (see Chapter 14). There is opportunity here for focused research on development of appropriate standards and evaluation of effectiveness of these technologies.

MOCHA itself has managed in a modest way to kick-start linkage with the Trillium II project (https://trillium2.eu/) on Patient Summaries led by the European office of the HL7 Foundation and created a strong interest within that project in focusing on children's record summaries (see Chapter 14). However, this work is unfunded. The wish and potential opportunity are to 
commence with immunisation (involving also the European Centre for Disease Control (ECDC)), then move on to other child record aspects and possibly to interact with WHO in the optimisation and standardisation of data contained in national schemes for Home-based Records (see Deshpande, Rigby, Alexander, \& Blair, 2018).

MOCHA has also identified the need for focussed research on the optimal data items in Electronic Health Records and for functionalities including algorithms for disease detection and other child EHR decision support applications. Indeed, as reported in Chapter 14, this need has been identified globally but is not being addressed. It could be a valuable field in which Europe could show leadership through its active e-health programme.

\section{Collaborative and Harmonised Use of Downloaded Research Databases}

In Chapter 7, we described the initiative within MOCHA to identify the many research databases in Europe compiled from operational record systems. We identified 147 of these relevant to evaluation of primary care for children, but in the event, very few could be used within the resources and timescale of the project, despite the willingness of each one to be registered with the project and to complete a metadata collation. Barriers included variation in data models and data representation, lack of resource at the individual database management level, setting of prohibitive fees and also the need to seek ethical approval for each enquiry for each database.

Exploitation within an ethical framework of very large databases is a much advocated new dimension to health research. Europe could set a lead on this not least from the degree of opportunity we have identified. And given the paucity of data on children's health care, there is a very large need waiting to be met. We also recommend that there should be developed a common large database research governance framework which is operationalised across the EU. Ethical guidelines and a high-level ethical process could be defined collaboratively at EU level with the intention of establishing key ethical principles and codes of conduct and above all mutual recognition. Existence of this during our work could have led to much more robust evidence for our findings.

\section{Promoting Child Rights and Equity}

Europe is rightly strong on the principle of supporting Children's Rights, and indeed, DG Justice leads on monitoring this. However, many rights are focussed in high-level terms and are difficult to make meaningful at child level. The MOCHA project has sought to be innovative in selecting a number of rights statements and framing service delivery principles for child primary care as a means of delivering on those rights - see Chapter 4. Not only is further work needed to find parallel underpinning healthcare evidence, but also this initiative could be developed into a more proactive rights-achieving initiative. 
Further means of monitoring equity are also needed. Chapters 5 and 8 show the current paucity of effective measurement in this field, due to a considerable degree to the lack of child-centric published data.

\section{Recognising Children's Evolving Autonomy}

Throughout this report, we have demonstrated the need for health practitioners and services to adapt to the evolving autonomy of the child and young person, whether through improved communications skills or decision making regarding treatment or developing salutogenic behaviours. Yet, technically in most countries, the law considers children to be dependents until their 18th birthday (or in some respects, until 16 years). In our work on human papilloma virus immunisation, we found countries where parents could veto the child having the protection, or conversely compulsorily injecting the child at the parent's request.

However, children are not dependent infants for 17 years - they are increasingly enquiring, active and responsible human beings seeking to set their own course in life, adjusted to their own characteristics. Europe has recognised that this simple 'incompetent unless fully competent' attitude is inappropriate for older citizens, whose drive and whose cognitive ability may gradually reduce, but who do not want a sudden and irreversible progression from legal competence to legal dependence. Hence, Europe has initiated opportunities and frameworks for assisted decision-making, whereby the citizen can delegate (or be relieved of) some responsibilities, while still being able to express basic preferences and choices. We believe that there is an urgent need to initiate similar innovation for children, so that as their comprehension, decision-making and actions progressively increase, so they can formally express and have recorded their preferences and wishes. This was well demonstrated in Chapters 11 and 12. We see the scope for further work on this, with a view to developing a European set of principles matching at the early stage of life of the assisted decisionmaking principles for the late stages of life.

\section{Conclusion}

MOCHA set out with the goal of identifying through research the optimal models of primary care for children. For the reasons cited, this is an impossible challenge as environment and society so dominate citizen health, and acceptable means of delivering health care, that no one model will fit all. But we have seen the importance of evidence-based approaches and have been increasingly frustrated and saddened at the inability to marshal strong evidence, or undertake local comparisons, due to avoidable barriers. One barrier is the lack of focus on applied research to enhance children's healthcare systems - such as by being able to research relative importance of different professional skills or ehealth optimisation. The second is failure to marshal existing raw data into accessible information systems yielding data that matter about children. 
Yet despite these avoidable gaps, Europe has most if not all of the skills and organisations to enable better evidence to be created by applied research, and linked across European institutions and directorates, to lead to an improvement both in evidence-informed policy and in care delivery. Healthcare provision remains a national competence, but if Europe through further collaborative research could produce strong and convincing evidence on optimum components of models and design principles, thus enabling member states and populations to make evidence-informed informed decisions, this should have as much beneficial influence as European solidarity has had on, for example, environment, workplace safety or sustainability.

So in conclusion, our Optimal Model for Children's Primary Health Care in Europe is one where the European Commission is proactive, in a joined up corporate way, to enable and provide robust evidence on which member states and their populations and institutions can make informed policy decisions on intersectoral intervention on the wider determinants of child health, service structure, professional competencies, investment levels and child co-involvement in their health trajectory.

\section{References}

Deshpande, S., Rigby, M., Alexander, D., \& Blair, M. (2018). Home based records. Retrieved from www.childhealthservicemodels.eu/wp-content/uploads/R15-HomeBased-Records-Report.pdf

DG Employment, Social Affairs and Inclusion. (2018). European skills/competencies, qualifications and occupations. Retrieved from https://ec.europa.eu/esco/portal/home

European Commission. (2016). So what? Strategies across Europe to assess quality of care - Report by the expert groups on health systems performance assessment. Retrieved from https://ec.europa.eu/health/sites/health/files/systems_performance_ assessment/docs/sowhat_en.pdf

Kocken, P., Vlasblom, E., de Lijster, G., \& Reijneveld, M. (2018). Consensus statements of stakeholders on most optimal models of child primary healthcare with guidance on potential benefits and how these might be achieved. Retrieved from http://www.childhealthservicemodels.eu/wp-content/uploads/Deliverable-D18-9.2A-report-containing-consensus-statements-on-most-optimal-models-with-guidanceon-potential-benefits-and-how-these-might-be.pdf

Kringos, D. S., Boerma, W., van der Zee, J., \& Groenewegen, P. (2013). Europe's strong primary care systems are linked to better population health but also to higher health spending. Health Affairs, 32(4), doi:10.1377/hlthaff.2012.1242

Rigby, M. J., Köhler, L. I., Blair, M. E., \& Mechtler, R. (2003). Child health indicators for Europe - A priority for a caring society. European Journal of Public Health, 13(3 Supplement), 38-46.

Schloemer, T., \& Schröder-Bäck, P. (2018). Criteria for evaluating transferability of health interventions: A systematic review and thematic synthesis. Implementation Science, 13(1), 88. doi:10.1186/s13012-018-0751-8

van Til, J., Groothuis-Oudshoorn, K., \& Boere-Boonekamp, M., (2018). Public priorities for primary care for children. Retrieved from http://www.childhealthservicemodels.eu/publications/technical-reports/ 
World Health Organization Regional Office for Europe. (2018, June 13-14). Health systems for prosperity and solidarity: Leaving no-one behind. Tallinn, Estonia. Retrieved from http://www.euro.who.int/_data/assets/pdf_file/0008/373688/tallinnoutcome-statement-eng.pdf?ua=1

Zdunek, K., Schroder-Back, P., Rigby, M., \& Blair, M. (2018). The culture of evidence-based practice in child health policy - A report. Retrieved from http:// www.childhealthservicemodels.eu/publications/technical-reports/ 